\title{
Estilos Motivacionais de Professores: Propriedades Psicométricas de um Instrumento de Avaliação ${ }^{1}$
}

\author{
Sueli Édi Rufini Guimarães², José Aloyseo Bzuneck \\ Universidade Estadual de Londrina \\ Evely Boruchovitch \\ Universidade Estadual de Campinas
}

\begin{abstract}
RESUMO - O objetivo deste estudo foi submeter à análise fatorial exploratória um instrumento de avaliação de estilos motivacionais de professores, elaborado por Deci e colaboradores, denominado Problems in School. O teste original, na forma de escala Likert, considerava a existência de um continuum com quatro diferentes estilos que contribuem para a promoção da autonomia dos estudantes. Traduzido para o português, o teste foi aplicado a 582 professores do ensino fundamental e médio de diversas regiões do Brasil. Embora os resultados da análise fatorial tenham revelado uma solução de quatro fatores ortogonalmente distintos, a suposição inicial dos autores (existência do continuum) não foi confirmada. De fato, apenas dois estilos opostos (altamente promotores de autonomia e de controle) corresponderam à proposta original de Deci et al. Surgiram problemas em relação à validade dos demais estilos. Os resultados foram discutidos e uma versão revisada da escala foi desenvolvida. São também sugeridas direções para futuras pesquisas.
\end{abstract}

Palavras-chave: promoção da autonomia; avaliação de estilos motivacionais; motivação intrínseca; ensino e motivação.

\section{Teachers' Motivational Styles: Psychometric Characteristics of Assessment Instrument}

\begin{abstract}
The purpose of this study was to conduct an exploratory factorial analysis of Problems in School, a teachers' motivational styles evaluation instrument, constructed by Deci et al. The original instrument is in a Likert-scale format with the underlying assumption of the existence of a continuum of four different styles contributing to promote students' autonomy. Translated into portuguese, the instrument was applied to 582 elementary and junior high school teachers from several regions of Brazil. Factorial analyses revealed a solution with four orthogonal distinct factors, the authors' initial supposition (existence of a continuum) was not confirmed. In fact, only two opposite styles (both high promotion of autonomy and of control) corresponded to the Deci et al. original ideas. Problems regarding the validity of the other remaining styles emerged. Data was discussed and a revised version of the scale was developed. Directions for further research were also suggested.
\end{abstract}

Key words: autonomy support; motivational styles assessment; intrinsic motivation; motivation and teaching

Um aluno com motivação intrínseca em sala de aula caracteriza-se por curiosidade, interesse, atenção concentrada, persistência e um alto envolvimento nas atividades de aprendizagem, que são buscadas como um fim em si mesmas (Guimarães, 2001). Como se pode facilmente depreender dessa descrição, a motivação intrínseca é o estado educacionalmente mais desejável, tendo levado diversos autores a trabalhar na identificação dos fatores que a promovem e, por outro lado, que a possam comprometer. Envolvimento semelhante com a aprendizagem pode ser observado em situações nas quais, embora se evidencie a motivação extrínseca, a regulação externa é integrada aos valores e regulações do próprio aluno. É sugerido pelos autores um continuum de desenvolvimento da regulação, caminhando de um simples controle externo à auto-regulação do comportamento.

A Teoria da Autodeterminação (Deci \& Ryan, 1985; Ryan \& Deci, 2000) propõe que três principais componentes caracterizam a motivação intrínseca e as formas auto-reguladas

1 Os resultados da presente pesquisa foram apresentados na XXXI Reunião Anual de Psicologia, da Sociedade Brasileira de Psicologia. Rio de Janeiro, 2001

2 Endereço: Rua Rangel Pestana, n.340. apt ${ }^{\circ}$. 1301. Londrina Pr. CEP 86062-060 - E-mail: jsgj@uel.br de motivação extrínseca: o senso de autonomia, o senso de competência e a experiência de vínculo. Ao mesmo tempo, a teoria explicita as condições de sala de aula que os promovem e que, portanto, tornam os alunos intrinsecamente motivados e auto-regulados. Ou seja, para se conseguir esse tipo ideal de motivação, o ambiente educacional deve propiciar que os alunos experimentem liberdade para iniciar e regular o comportamento e que os faça sentirem-se competentes, emocional e pessoalmente ligados às pessoas.

Especificamente quanto à promoção da autonomia, Edward Deci e colaboradores (Deci, Schwartz, Sheinman, \& Ryan, 1981), no início dos anos 80, desenvolveram um questionário denominado Problems in Schools, destinado a avaliar o estilo motivacional de professores, ou seja, quais estratégias utilizam para formar alunos autônomos. Segundo os autores, podem ser identificados dois principais estilos distintos e opostos: o promotor de autonomia e o controlador. Os itens do questionário buscam avaliar esses dois estilos, incluindo adicionalmente os níveis intermediários de moderadamente controlador e moderadamente promotor de autonomia. O questionário, portanto, avalia o estilo motivacional do professor por meio de quatro variáveis: AA (alto promotor de autonomia), MA (moderado promotor de autonomia); MC (moderado controlador) e AC (alto controlador). 
O instrumento consta de oito vinhetas que descrevem cenários comuns às salas de aula, em que um aluno ou aluna apresenta algum problema comportamental ligado à motivação. Após cada vinheta, seguem-se quatro alternativas em forma de itens. Cada item representa um ponto no continuum que contempla uma das quatro posições desde altamente promotor de autonomia até altamente controlador. Além disso, cada item deve ser assinalado pelo professor numa escala de 1 a 7 , conforme ele julgar o grau de propriedade expressa na solução nele contida (desde muito impróprio até muito apropriado). Segue-se como exemplo a primeira vinheta, seguida das alternativas que lhe dizem respeito.

"Luís é um aluno médio, com desempenho no nível de sua classe. Entretanto, nas duas últimas semanas, ele parece desatento, apático e não tem participado do grupo deleitura. O trabalho que faz é bem feito, mas ele não tem completado as tarefas. Uma conversa pelo telefone com a mãe dele não trouxe informações úteis. A coisa mais apropriada para a professora de Luís fazer é:

(a) acentuar para ele a importância de terminar suas tarefas porque ele precisa aprender esse conteúdo para o seu próprio bem;

(b) informá-lo de que ele não precisa terminar todo o trabalho e verificar se ela pode ajudá-lo a descobrir a causa de sua desatenção;

(c) fazê-lo ficar depois da aula até o dia em que as tarefas sejam completadas;

(d) levá-lo a se comparar com os colegas no que diz respeito à realização das tarefas e encorajá-lo a alcançá-los."

A instrução que precedia o teste solicitava que cada professor marcasse, na escala de 1 a 7 , o total de 32 itens, produto de quatro itens para cada uma das oito vinhetas. No exemplo acima, e de acordo com critérios originalmente estabelecidos pelos autores, a alternativa (a) indica um estilo motivacional moderadamente controlador; a alternativa (b), estilo altamente promotor de autonomia; a alternativa (c), de alto controle; e a alternativa (d), de moderada autonomia. Os mesmos quatro estilos motivacionais estavam contemplados, em ordem aleatória, nos respectivos itens das demais vinhetas, chegando-se à soma final de oito itens para cada subescala representativa de um estilo.

\section{Pesquisas anteriores sobre o instrumento}

Em seu estudo original, Deci e cols. (1981) decidiram adotar uma ponderação em cima dos escores médios em cada uma das quatro subescalas. Desta forma, o escore final na subescala de estilo altamente controlador resultava do escore inicial pela marcação nos itens, multiplicado por -2; a subescala do estilo moderadamente controlador recebia o peso -1; a subescala de estilo moderadamente promotor de autonomia, +1; e, por fim, o altamente promotor de autonomia, +2 . Portanto, o escore total na escala varia desde -18 até +18 . Quanto mais alta a média final, configura-se maior promoção de autonomia e vice-versa. Além disso, os autores, ao trabalharem com uma amostra de 68 professores do ensino fundamental, utilizaram-se dos seguintes procedimentos para identificar as propriedades psicométricas do instrumento: (a) a estatística descritiva das quatro subescalas e o escore total na escala (desde -18 até +18$)$; (b) correlações entre os itens individuais e os totais na quatro subescalas; (c) coeficientes alfa das metades da partição em cada uma das subescalas; (d) correlações entre o escore em cada subescala com o escore em cada uma das demais; (e) índice de fidedignidade entre teste e reteste dois meses após, com uma subamostra de 19 professores. Finalmente, a validade externa da escala foi testada em relação a 35 professores, mediante o levantamento das percepções de seus respectivos alunos do clima de sua sala de aula, de sua motivação intrínseca e da auto-estima.

Os resultados dos estudos de Deci e cols. (1981) revelam notável consistência interna entre os itens de cada subescala, além de estabilidade temporal dos resultados no intervalo de dois meses. A validade externa também foi confirmada. Entretanto, os autores tiveram que admitir que a subescala do estilo "moderado promotor de autonomia", por carregar acentuadamente em comparações sociais, tem mais características de um estilo controlador do que eles supunham originalmente.

Posteriormente, o instrumento original Problems in Schools foi utilizado em pesquisas como as de Deci, Spiegel, Ryan, Koestner e Kauffman (1982), Flink, Boggiano e Barrett (1990), Woolfolk e Hoy (1990), Reeve (1998); Guay, Boggiano e Vallerand (2001) e em Yi Cai, Reeve e Robinson (2002). Nenhuma delas, porém, teve a preocupação de avaliar as propriedades psicométricas em termos de identificação de fatores subjacentes.

Reeve, Bolt e Cai (1999) demonstraram lacunas e falhas no desenvolvimento e aplicação do referido instrumento em pesquisas e objetivaram corrigi-las para uso em investigações subseqüentes. A primeira falha, segundo os autores, referese aos resultados das análises estatísticas realizadas para validação inicial do teste. Em decorrência de novas análises correlacionais entre as variáveis e de testes de consistência interna das questões propuseram fórmulas alternativas para a avaliação numérica do desempenho dos professores no teste. Uma lacuna constatada seria proveniente da falta de estudos visando relacionar os resultados obtidos no questionário e as interações promovidas em sala de aula. A pesquisa de Reeve e cols. (1999), utilizando uma situação de ensino controlada, de laboratório, confirmou padrões interativos diferenciados entre professores com alto e baixo desempenho no teste, ou seja, professores promotores de autonomia e controladores. Neste aspecto, observações de situações reais de sala de aula poderiam ampliar o conhecimento sobre as possibilidades de identificação dos estilos motivacionais oferecidas pelo questionário. Por último, os autores destacam que, atualmente, descobrir as formas específicas através das quais professores promotores da autonomia motivam e ensinam seus alunos e, por outro lado, conhecer as relações entre as variáveis sóciocontextuais (tempo de experiência no ensino, horas semanais trabalhadas, número de alunos por classe) e a opção por determinado estilo motivacional são importantes problemas a serem investigados.

Reconhecendo que as pesquisas na área da motivação e aprendizagem escolar são recentes e reduzidas na realidade brasileira e que mais raros ainda são os estudos que focalizam aspectos metodológicos, envolvendo instrumentos de medida, buscar alternativas metodológicas para o desenvolvimento de investigações nesse campo, em nosso meio, é uma tarefa importante. Nesse sentido, a tradução, adaptação 
e sobretudo a validação de instrumentos já consolidados por pesquisas em outros países representa um dos caminhos a serem trilhados para o desenvolvimento da área. Em última instância, a elaboração de novos instrumentos propiciará o conhecimento mais acurado de nossa realidade educacional, apontando novas alternativas para a melhoria no ensino nos diferentes níveis.

O objetivo fundamental do presente estudo consistiu no levantamento das propriedades psicométricas do instrumento desenvolvido por Deci e cols. (1981), traduzido para o português, em relação às quatro variáveis de estilo motivacional teoricamente relevantes. Isto é, mediante análise fatorial convencional exploratória, através da extração dos componentes principais, buscou-se identificar os fatores subjacentes aos 32 itens do estudo original, inclusive quanto à sua correspondência com os quatro pontos do continuum, expressos nos pressupostos teóricos.

\section{Método}

\section{Participantes}

Participaram do estudo 582 professores e professoras do ensino fundamental e médio, atuando em cinco diferentes estados brasileiros: diversas cidades do Paraná, de São Paulo, capital e interior, do Vale do Itajaí (SC), de Campo Grande (MS) e do interior da Bahia.

Do total dos professores participantes, $381(66,49 \%)$ tinham idades acima de 31 anos, seguidos por $169(24,49 \%)$ na faixa de 23 a 30 anos. Apenas $23(4,01 \%)$ professores tinham até 22 anos. A grande maioria dos participantes era do sexo feminino $516(90,05 \%)$, contra apenas $57(9,94 \%)$ do sexo masculino. A formação acadêmica de 570 professores variou do ensino médio à pós-graduação, sendo $288(50,52 \%)$ graduados, $219(38,42 \%)$ pós-graduados e $63(11,05 \%) \mathrm{com}$ apenas o ensino médio. Quanto ao tempo de atuação no magistério, de 417 professores $220(48,14 \%)$ tinham 11 anos ou mais; $115(33,91 \%)$ de quatro a dez anos e $82(17,94 \%)$ até três anos de experiência. De 544 professores, 324 (59,55\%) atuavam apenas em uma escola, $171(31,43 \%)$ em duas escolas e 49 (9\%)em três ou mais escolas. Em relação ao número de turmas de estudantes que atendiam, $163(30,58 \%)$ tinham apenas uma turma, $90(16,88 \%)$ duas turmas e $19(3,56 \%)$ três turmas, sendo que as turmas, em média, eram formadas por 35 alunos.

\section{Procedimentos}

Após a obtenção do teste e da autorização dos autores para uso em pesquisas, foi realizada tradução inicial para o português, sendo que alguns termos e situações específicas da cultura americana foram adaptados para nossa realidade, havendo o cuidado mantê-lo o mais próximo possível do original. Em seguida, outro pesquisador realizou a versão do questionário para o inglês (back translation), sendo então comparada com o original em inglês. As discrepâncias percebidas foram verificadas e discutidas, resultando na tradução definitiva do questionário para o português. Este cuidado no procedimento de tradução possibilitou uma versão equivalente à original do ponto de vista lingüístico e semântico.
Após a versão definitiva para o português, o questionário foi aplicado a uma amostra de 20 professores do Ensino Fundamental com o objetivo de levantar possíveis dificuldades na compreensão do conteúdo e da linguagem, assim como estimar o tempo necessário para sua execução. Nesse procedimento, os participantes foram informados que deveriam assinalar as possíveis dúvidas e dificuldades para responder o questionário. Os participantes não apontaram dificuldades e o tempo médio necessário para completá-lo foi em torno de 15 minutos.

Os 582 professores participantes foram abordados e aceitaram responder ao $P S$ em situações diferentes. Alguns foram contatados durante a sua participação em cursos de capacitação ou de graduação ou de pós-graduação, outros foram procurados em seu local de trabalho, após autorização da administração da escola, em reuniões de professores, no intervalo entre as aulas. Em certos casos, supervisores ou coordenadores pedagógicos das escolas foram informados sobre os objetivos e as exigências para a aplicação do teste e se encarregaram de levá-lo até os professores. As duas últimas alternativas (contato direto com o professor na escola durante o intervalo e através do supervisor) apresentaram dificuldades quanto ao retorno do questionário. Como o tempo necessário para seu preenchimento variou em torno de 15 minutos, o professor optava por levá-lo para casa e concordava em entregá-lo posteriormente. Poucos, no entanto, cumpriam o combinado. A aplicação foi em parte realizada pelo primeiro autor deste trabalho e em parte por dois colegas e uma aluna de Pedagogia da mesma Universidade, contando-se ainda com a colaboração de supervisores e diretores de escolas, que se responsabilizaram pelo contato com os professores.

\section{Resultados}

Os 32 itens foram submetidos à análise fatorial com extração dos componentes principais com rotação varimax. A tabela 1 mostra dez fatores resultantes, com valor próprio ( $e i$ genvalue) maior que 1 , respondendo por $57,10 \%$ da variância nos escores dos participantes. A figura 1 representa os valores próprios e os componentes principais, sendo cada inclinação da reta o ponto de rotação de cada fator encontrado.

Entretanto, foram aqui adotados apenas os quatro fatores com valor próprio mais alto, que corresponderiam às quatro subescalas com relevância teórica. Esses escores explicam

Tabela 1. Extração de componentes principais, com valor próprio maior que 1,00 .

\begin{tabular}{lcccc}
\hline Fator & $\begin{array}{c}\text { Valor } \\
\text { próprio }\end{array}$ & $\begin{array}{c}\text { Explicação } \\
\text { \% }\end{array}$ & $\begin{array}{c}\text { Valor } \\
\text { próprio } \\
\text { acumulado }\end{array}$ & $\begin{array}{c}\text { Explicação \% } \\
\text { acumulada }\end{array}$ \\
\hline 1 & 5,21 & 16,30 & 5,21 & 16,30 \\
2 & 2,61 & 8,16 & 7,82 & 24,46 \\
3 & 1,71 & 5,34 & 9,54 & 29,81 \\
4 & 1,54 & 4,81 & 11,08 & 34,63 \\
5 & 1,41 & 4,40 & 12,49 & 39,03 \\
6 & 1,34 & 4,20 & 13,83 & 43,24 \\
7 & 1,18 & 3,70 & 15,02 & 46,95 \\
8 & 1,12 & 3,51 & 16,15 & 50,47 \\
9 & 1,07 & 3,37 & 17,23 & 53,84 \\
10 & 1,04 & 3,25 & 18,27 & 57,10 \\
\hline
\end{tabular}




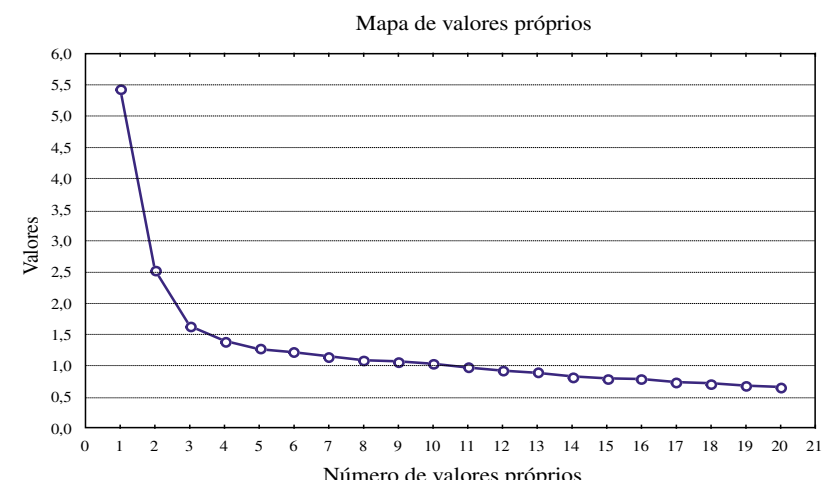

no conjunto $34,63 \%$ da variância, e com um alfa de Cronbach 0,82 .
Individualmente, o fator 1 apresenta um grau de homogeneidade entre seus itens representado por alfa $=0,76$; o fator 2 , alfa $=0,60$; o fator 3 , alfa $=0,66$; e o fator 4 , alfa $=0,62$.

A tabela 2 ilustra a extração das cargas fatoriais de cada item, após a rotação varimax, ou seja, a correlação de cada item do questionário com os quatro fatores considerados. Observe-se na tabela que cada item é seguido, entre parênteses, do tipo de estilo motivacional, conforme fora proposto pelos autores do instrumento. Na presente análise, para que um item do questionário pudesse carregar num fator, estabeleceu-se como critério o valor de corte de 0,30. De acordo com Kline (1994), este é um valor aceitável, dado que explicaria pelo menos $9 \%$ da variância total. Desta forma, dois itens da estrutura original foram descartados e já não aparecem nessa tabela. O item 1C (fazê-lo ficar após a aula até o dia em que

Tabela 2. Extração das cargas fatoriais dos diferentes itens, com rotação varimax.

\begin{tabular}{|c|c|c|c|c|c|}
\hline Item & & Fator 1 & Fator 2 & Fator 3 & Fator 4 \\
\hline 1D & Levá-lo a se comparar com os colegas no que diz respeito à realização de tarefas e encorajá-lo a alcançá-los (MA) & 0,62 & & & \\
\hline 2B & Dizer que está se saindo tão bem Quanto seus outros colegas de classe(MA) & 0,54 & & & \\
\hline $3 \mathrm{C}$ & Ajudá-lo a observar como as outras crianças se comportam e elogiar por fazer o mesmo (MA) & 0,65 & & & \\
\hline $4 \mathrm{C}$ & Ver se os outros estão na mesma situação e sugerir que se prepare tanto Quanto os demais (MA) & 0,63 & & & \\
\hline $5 \mathrm{~A}$ & Promover atividades regulares para que os alunos motivem-se a se sair tão bem quanto outros grupos (MA) & 0,43 & & & \\
\hline $6 \mathrm{~A}$ & Estimular a agir socialmente e elogiar qualquer iniciativa de sua parte (AC) & 0,33 & & & \\
\hline $6 \mathrm{~B}$ & Falar com ela e enfatizar que deve fazer mais amigos para que seja mais feliz (MC) & 0,41 & & & \\
\hline $6 \mathrm{D}$ & Encorajá-la a observar como as outras crianças relacionam-se e incentivá-la a unir-se a elas (MA) & 0,68 & & & \\
\hline 1B & Informar que não precisa terminar todo o trabalho verificar se pode ajudar descobrir a causa da desatenção (AA) & & 0,43 & & \\
\hline $2 \mathrm{C}$ & $\begin{array}{l}\text { Falar sobre o seu progresso mostrando que sabem que ela está se tornando cada vez mais independente na escola } \\
\text { e em casa (AA) }\end{array}$ & & 0,50 & & \\
\hline $3 \mathrm{D}$ & Perceber que não está recebendo a atenção que necessita e começar a lhe dar mais atenção (AA) & & 0,60 & & \\
\hline $4 \mathrm{~A}$ & Pedir que conte sobre seus planos para lidar com a situação (AA) & & 0,51 & & \\
\hline $5 \mathrm{D}$ & Ajudar o grupo a desenvolver maneiras de aprender palavras juntos (AA) & & 0,54 & & \\
\hline $6 \mathrm{~A}$ & Estimular a agir socialmente e elogiar qualquer iniciativa de sua parte (AC) & & 0,35 & & \\
\hline $6 \mathrm{C}$ & $\begin{array}{l}\text { Convidá-la a falar sobre suas relações com outras crianças e encorajá-la a dar passos pequenos Quando ela se } \\
\text { sentir pronta para isso (AA) }\end{array}$ & & 0,53 & & \\
\hline 7B & Conversar sobre o assunto expressando sua confiança e tentando compreender porque fez isso (AA) & & 0,47 & & \\
\hline $8 \mathrm{~A}$ & Encorajá-lo a falar sobre suas notas e sobre o que significam para sua vida (AA) & & 0,38 & & \\
\hline $1 \mathrm{~A}$ & Acentuar a importância de Terminar a tarefa ele precisa aprender o conteúdo para seu próprio bem (MC) & & & 0,52 & \\
\hline $2 \mathrm{D}$ & Continuar enfatizando que ela deve continuar estudando bastante para conseguir melhores notas (MC) & & & 0,41 & \\
\hline $3 \mathrm{~A}$ & Enfatizar o Quanto é importante se controlar para se sair bem na escola e em outras situações (MC) & & & 0,56 & \\
\hline $7 \mathrm{~A}$ & $\begin{array}{l}\text { Falar sobre as conseqüências de roubar e o que isso representa para o seu relacionamento com as outras crianças } \\
\text { (MA) }\end{array}$ & & & 0,58 & \\
\hline 7C & Dar-lhe uma boa repreensão, ele tem que aprender isso (AC) & & & 0,50 & \\
\hline 7D & Enfatizar que foi errado, fazer com que peça desculpas e prometa não fazer mais isso (MC) & & & 0,59 & \\
\hline $8 \mathrm{~A}$ & Encorajá-lo a falar sobre suas notas e sobre o que significam para sua vida (AA) & & & 0,32 & \\
\hline $8 \mathrm{C}$ & Ressaltar que deve ir melhor e que com essas notas jamais entrará em uma universidade (MC) & & & 0,36 & \\
\hline $2 \mathrm{~A}$ & Premiá-la e prometer-lhe um prêmio especial se continuar melhorando (AC) & & & & 0,43 \\
\hline 3B & Encaminhá-lo para uma classe especial que tenha estrutura e possibilidades de recompensas que ele precisa (AC) & & & & 0,56 \\
\hline 4B & Dizer que deve decidir adiar o jogo para estudar (MC) & & & & 0,52 \\
\hline $4 \mathrm{D}$ & Fazer com que falte o jogo, o futebol tem interferido demais com seu desempenho escolar (AC) & & & & 0,58 \\
\hline 5B & Fazê-los praticar mais e dar-lhes privilégios especiais pelos seus progressos (AC) & & & & 0,41 \\
\hline $8 \mathrm{~B}$ & Pegar seu boletim e compará-lo com o dos colegas, mostrar sua colocação na classe (MA) & & & & 0,53 \\
\hline $8 \mathrm{D}$ & Oferecer 1 Real por cada conceito A e 50 centavos por cada conceito B nos próximos boletins (AC) & & & & 0,40 \\
\hline
\end{tabular}


sejam completadas) e 5C (fazer um gráfico sobre o desempenho e enfatizar que é importante ter um bom desempenho) não atingiram a carga de pelo menos 0,30 em nenhum fator. Observe-se, por outro lado, que o item 6A (estimular a agir socialmente e elogiar qualquer iniciativa de sua parte) carregou nos fatores 1 e 2 . O item $8 \mathrm{~A}$ (encorajá-lo a falar sobre suas notas e sobre o que significam para sua vida), por sua vez, carregou tanto no fator 2 como no 3 . Esse detalhe exigiu uma tomada de decisão, que será relatada mais adiante.

Levantaram-se igualmente as correlações entre as quatro variáveis, como se pode ver na Tabela 3. Os escores médios na variável estilo moderadamente promotor de controle correlacionam-se em nível moderado e significativo com os escores médios nas variáveis alto controle e moderado promotor de autonomia. Esse resultado é similar à correlação entre alto controle e moderada autonomia. Já o estilo altamente promotor de autonomia tem correlação próxima de zero com alto controle e correlação discreta com moderada autonomia. Portanto, mediante esse tratamento estatístico, o estilo altamente promotor de autonomia parece emergir como mais definido, com relativa independência dos demais estilos.

Tabela 3. Correlações entre as médias obtidas nas quatro escalas, excluídos os itens com baixa carga fatorial

\begin{tabular}{lcccc}
\hline & AA & MA & MC & AC \\
\hline AA & 1,00 & $0,19^{*}$ & $0,15^{*}$ & 0,03 \\
MA & & 1,00 & $0,50^{*}$ & $0,50^{*}$ \\
MC & & 1,00 & $0,45^{*}$ \\
AC & & & & 1,00 \\
\hline
\end{tabular}

$* p=0,001$

Tabela 4. Estatística descritiva dos resultados obtidos nas escalas de avaliação dos estilos motivacionais Alto promotor de autonomia (AA), moderado promotor de autonomia (MA), moderado controlador (MC) e alto controlador (MC), atendendo-se a dois critérios de tratamento dos itens.

\begin{tabular}{lccccccc}
\hline \multirow{2}{*}{ Variáveis } & \multicolumn{3}{c}{ Pelo gabarito original } & & \multicolumn{2}{c}{ Após a análise fatorial } \\
\cline { 2 - 3 } \cline { 7 - 8 } & $N$ & Média & Dp & & $N$ & Média & Dp \\
\hline AA & 570 & 6,07 & 0,69 & & 570 & 6,09 & 0,70 \\
MA & 567 & 4,32 & 1,11 & & 571 & 4,50 & 1,30 \\
MC & 566 & 4,73 & 1,07 & & 568 & 4,93 & 1,12 \\
AC & 568 & 3,06 & 0,84 & & 573 & 2,71 & 1,04 \\
\hline
\end{tabular}

Tabela 5. Correlações de Pearson entre os escores médios grupais nas quatro subescalas, obtidos segundo o gabarito original dos autores e os obtidos após a análise fatorial.

\begin{tabular}{lcccc}
\hline \multirow{2}{*}{$\begin{array}{c}\text { Pelo gabarito } \\
\text { Original/ }\end{array}$} & \multicolumn{4}{c}{ Escores definidos após análise fatorial } \\
\cline { 2 - 5 } & $\mathbf{A A}$ & $\mathbf{M A}$ & $\mathbf{M C}$ & $\mathbf{A C}$ \\
\hline $\mathbf{A A}$ & $0,97^{* *}$ & $0,16^{* *}$ & $0,10^{*}$ & 0,00 \\
$\mathbf{M A}$ & $0,20^{*}$ & $0,94^{* *}$ & $0,56^{* *}$ & $0,52^{* *}$ \\
$\mathbf{M C}$ & $0,17^{*}$ & $0,68^{* *}$ & $0,83^{* *}$ & $0,66^{* *}$ \\
$\mathbf{A C}$ & $0,10^{*}$ & $0,51^{* *}$ & $0,54^{* *}$ & $0,88^{* *}$ \\
\hline$* p=0,01$ & & & & \\
$* * p=0,001$ & & & & \\
\end{tabular}

Os dados obtidos com a presente amostra foram, além disso, analisados com base no critério original de aglutinação dos itens que formavam as quatro variáveis do continuum (Deci \& cols., 1981) e, comparativamente, com base na extração fatorial. Em outras palavras, buscou-se verificar o grau de semelhança entre os escores médios da amostra obtidos com o critério do gabarito dos autores do teste com os escores médios obtidos após a distribuição pelos fatores. A tabela 4 apresenta as médias de acordo com os dois métodos. A tabela 5 mostra as correlações entre os escores médios, pelos dois métodos.

\section{Discussão}

O objetivo geral deste estudo foi verificar as propriedades psicométricas do questionário Problems in Schools, de Deci e cols. (1981). Mais especificamente, buscou-se descobrir se as quatro variáveis representativas de diferentes estilos motivacionais de professores correspondem a quatro fatores ortogonalmente distintos. A se atingir tal objetivo, mediante a análise fatorial exploratória, se conseguiria uma forma de validação do instrumento originalmente proposto pelos autores, o que representaria um avanço além da simples pontuação daquelas variáveis no continuum. A lógica parece exigir que, mesmo que se adote o critério do continuum, cada estilo motivacional se revista de características de independência conceitual e que assim seja identificado nas mensurações.

Na elaboração dos itens do questionário os autores buscaram retratar o estilo motivacional do professor a partir de um continuum desde o estilo altamente controlador até altamente promotor de autonomia. Analisando as justificativas dos autores sobre a elaboração dos itens de cada subescala, evidencia-se um embasamento na idéia de continuum de desenvolvimento da autodeterminação. Nesta perspectiva teórica (Ryan \& Deci, 2000) considera-se a existência de uma tendência natural humana para transformar valores e regulações externas em processos de regulação interna. $\mathrm{O}$ caminho parte de um ponto inicial de total regulação externa e culmina na regulação integrada, situação na qual os valores e regulações externas integram-se ou, em outras palavras, passam a fazer parte do conjunto de valores e regulações do indivíduo. Esse processo tem sido denominado de internalização.

Assim, as questões referentes a um maior controle por parte do professor retratariam o uso instrumental da regulação externa, ou seja, a utilização de motivadores extrínsecos para encorajar comportamentos apropriados. As questões próximas à promoção de autonomia proporiam a integração da regulação externa aos valores e regulações pessoais da criança, através de situações que a encorajariam a diagnosticar o problema, gerar uma solução e tentá-la de modo independente.

Os objetivos propostos como norteadores para a elaboração dos itens de cada subescala, no entanto, não parecem terem sido plenamente alcançados, como será apontado a seguir. A discussão que ora se inicia contempla a distribuição constante da tabela 2 .

A análise fatorial com rotação varimax de fato concluiu ser possível a partição em quatro fatores, compondo quatro subescalas distintas. As correlações entre os escores obtidos 
com a amostra, após a análise fatorial, e os obtidos em obediência ao gabarito inicial dos autores revelam que não existe uma plena concordância. A principal razão estaria no fato de que alguns itens do teste original ou são ambíguos ou não carregam no fator para o qual foram pensados. Desta forma, em relação aos dados da presente amostra, convém analisar cada um dos quatro fatores com os itens que nele atingiram uma determinada carga.

Verifica-se ainda um outro problema levantado pela presente análise fatorial e que diz respeito ao significado de cada fator, ou seja, existem problemas conceituais na interpretação da própria estrutura de fatores. Como observaram Tschannen-Moran e Hoy (2001), ao discutirem tipos de mensuração da auto-eficácia, muitas medidas revelam uma estrutura de fatores quando submetidas à análise fatorial, mas persiste discussão e até confusão quanto ao significado desses fatores. Em outras palavras, a mensuração que atenda às propriedades de validade pela descoberta de fatores pode ainda não atingir a validade de constructo. Essa observação parece aplicar-se ao presente caso, especialmente ao se focalizarem determinados itens.

Assim, em relação ao fator 1 , cujos itens haviam sido propostos como representativos de um estilo moderadamente promotor de autonomia, a proposta original dos autores foi apresentar situações que encorajassem a criança a ter empatia pela forma de o professor compreender, diagnosticar e solucionar o problema, havendo um esforço para que a criança compare a regulação externamente apresentada com seus próprios valores e regulações Tais situações, hipoteticamente, apoiariam o desenvolvimento da criança para uma regulação identificada, ou seja, a regulação é aceita pela pessoa, mas ainda é percebida como externa. No entanto, o conteúdo dos itens que compõem a subescala tem um claro apelo à comparação social, o qual não parece encorajar a empatia da criança para com as proposta do professor para a solução do problema. Além disso, a rotação da análise fatorial colocou no fator 1 dois itens que merecem análise. Trata-se do item 6A (estimular a agir socialmente e elogiar qualquer iniciativa de sua parte) e do item 6B (falar com ela e enfatizar que deve fazer mais amigos para que seja mais feliz). O primeiro desses itens havia sido pontuado, na proposta original dos autores, como representante de um estilo altamente promotor de controle, o que o tornaria deslocado entre os demais do fator 1. Mais ainda, esse mesmo item também carregou para o fator 2. Donde, há razões para que esse item 6A seja excluído da escala. O outro item em questão é o 6B, que havia sido caracterizado pelos autores como componente do estilo moderadamente controlador. À parte a discussão ainda pendente sobre qual seria a diferença substancial entre um estilo moderadamente promotor de autonomia e o moderadamente promotor de controle, parece que esse item 6B é qualitativamente diferente de todos os demais que formariam o estilo representado pelo fator 1 . Por enfatizar que o aluno deve fazer mais amigos - uma posição típica de entrosamento ou vínculo -, esse item distancia-se de todos os demais itens restantes dessa subescala, que enfatizam comparação social. Adicionalmente, excluído também o item $6 \mathrm{~B}$, o fator 1 poderia mais adequadamente ser rotulado de estilo promotor de comparação social, com seis afirmativas.

Já na elaboração dos itens que compuseram a subescala de alta promoção de autonomia, identificados no fator 2 , extraído através da análise fatorial, os autores buscaram situações nas quais os professores encorajassem a criança a compreender as causas do problema, buscar soluções de modo independente e tentar colocá-las em prática. Essas situações, em tese, incentivariam a criança a progredir no continuum de desenvolvimento da autodeterminação, alcançando a regulação integrada.

Assim, em relação a esse fator 2, sete entre os seus nove itens decorrentes da análise fatorial correspondem de forma inequívoca ao estilo altamente promotor de autonomia, como fora proposto pelos autores do teste. O item 6A (estimular a agir socialmente e elogiar qualquer iniciativa de sua parte) - além de haver carregado nesse fator e, simultaneamente, no fator 1, não se coaduna com os demais itens desta subescala por haver sido proposto como indicador de alto controle. Outra afirmativa, o item 8A, além de carregar para o fator 2, carregou para o fator 3 , identificado como estilo moderadamente controlador. Portanto, considerada a ambiguiidade de sua interpretação, é razoável que esse item seja igualmente eliminado da lista de itens que compõem o fator 2. Em suma, pode-se concluir que, uma vez escoimados esses dois itens, todos os demais que carregam no fator 2 correspondem inequivocamente ao que fora definido pelos autores e previsto no teste original. Isto significa que um professor que praticar as ações correspondentes aos itens finais pertencentes ao fator 2 estará seguramente promovendo a autonomia e a motivação intrínseca dos alunos.

$\mathrm{O}$ fator 3 corresponderia à subescala original de estilo moderado controlador, apresentando situações nas quais o professor identifica uma solução e encoraja sua implementação por apelar ao senso internalizado de "obrigação" do aluno. Neste caso, o ponto do continuum denominado regulação introjetada parece ter norteado a elaboração dos itens. Oito itens tiveram carga fatorial suficiente, porém apenas cinco deles conservam equivalência conceitualmente incontestável com a classificação original dos autores. Outros três itens merecem destaque. O primeiro deles é o 7 A (falar sobre as consequiências de roubar e o que isso representa para seu relacionamento com outras crianças), que Deci e cols. (1981) haviam codificado como moderado promotor de autonomia, o que o aproxima muito da subescala do fator 3 , ora em foco, de estilo moderado controlador. Por esse motivo, ao menos tentativamente poderia ser mantido nesta subescala. O segundo item problemático é 7C (dar-lhe uma boa repreensão, ele tem que aprender isso), cogitado como representativo de estilo alto controlador. E, por fim, temos o item 8A (encorajá-lo a falar sobre suas notas e sobre o que significam para sua vida) com carga relativamente baixa em dois fatores ( 2 e 3), ou seja, que pode ser considerado ou como altamente promotor de autonomia ou como moderadamente controlador. Como solução, poderia ser excluído de ambas as subescalas, valendo a mesma decisão para o item 7C, em função de seu caráter altamente controlador.

O fator 4 corresponderia ao estilo altamente controlador, no extremo oposto do continuum da autonomia. Os autores tiveram como norteador para a elaboração dos itens dessa subescala o ponto inicial do continuum de desenvolvimento da regulação externa, o reforçamento clássico do comportamento. Os itens da subescala consistem em situações nas quais o professor identifica uma solução para o problema 
e utiliza motivadores extrínsecos para os comportamentos apropriados. Entretanto, dois de seus sete itens, 4B (dizer que deve decidir adiar o jogo para estudar) e 8B (pegar seu boletim e compará-lo com o dos colegas, mostrar sua colocação na classe), pertencem conceitualmente a outros estilos, em aparente dissonância com os demais que compõem o fator 4 . Aliás, o item 4B havia sido com razão proposto pelos autores como indicador do estilo moderado controlador e o item 8B como indicador de promotor moderado de autonomia. Desta forma, embora a análise fatorial tenha carregado esses dois itens no fator 4, existem motivos para que não sejam mantidos nele.

Os demais itens que carregam no fator 4 têm consistência entre si no aspecto de que exprimem formas de controle do professor mediante a promessa de recompensas ou retirada de algum privilégio. De um ponto de vista teórico, o uso de recompensas externas como estratégia motivacional pode, via de regra, embora não necessariamente, representar formas de controle. De acordo com Lepper e Hodell (1989), toda a literatura em torno das recompensas externas permite a conclusão de que, ao lado das funções de feedback e de instrumentalidade, elas podem ser utilizadas como formas de pressão sobre os alunos.

Desta forma, há que rever a escala originalmente proposta pelos autores com 32 itens, distribuídos pelas quatro subescalas que compõem o continuum dos diferentes estilos de promoção da motivação. Consideradas as incongruências acima apresentadas e resolvidas, após a exclusão liminar de dois itens que não tiveram carga fatorial mínima estabelecida pelo valor de corte - $1 \mathrm{C}$ e $5 \mathrm{C}$ - , é razoável que se mantenham os quatro fatores ou subescalas, porém com nova composição de itens. O somatório será de 24 itens, contra os 32 da proposta original. Assim, o fator 1 - MA - contaria apenas com seis itens; o fator 2 - AA - com sete itens; o fator 3 - MC - com seis itens; e o fator 4 - AC -, com cinco itens. Essa nova configuração da escala pode ser visualizada na Tabela 6. Não se pode ainda concluir, porém, que essa seria a escala definitiva.

Resta ainda discutir a conciliação entre o estabelecimento de fatores ortogonais e a idéia das quatro variáveis num continuиm, defendida originalmente pelos autores (Deci e cols., 1981), no âmbito de sua teoria da autodeterminação. Os presentes resultados apontam para a impossibilidade de se manter aquela proposta do continuum, caso se adote a presente escala com as quatro variáveis.

Como já foi sugerido mais acima, as medidas que compõem tanto o fator 2 como o fator 4 estariam, sem dúvida, medindo dois estilos diametralmente opostos, ou seja, respectivamente, um estilo altamente promotor de autonomia e um estilo altamente controlador. Tal conclusão, já alcançada em estudos como o de Reeve e cols. (1999), poderia receber suporte definitivo em pesquisas que, entre outros possíveis procedimentos, adotassem a análise fatorial confirmatória.

Entretanto, mesmo após a depuração dos itens, as outras duas subescalas precisam ser reavaliadas quanto ao que estariam medindo, ou seja, há um problema de identificação dos respectivos constructos. Existem fortes indicadores de que os itens do fator 1, cogitado originalmente como indicativo de estilo moderado promotor de autonomia, estariam medindo estratégias de ensino que levam à comparação social.
Neste caso, dificilmente poderia continuar a ser rotulado de estilo apenas moderado promotor de autonomia. Deci e cols. (1981) já haviam encontrado dificuldade com essa subescala. As correlações com as outras subescalas levaram aqueles autores a concluir em seu estudo original que a subescala de avaliação do estilo "moderado promotor de autonomia" deveria mais apropriadamente chamar-se de estilo "levemente controlador". Além disso, Reeve e cols. (1999) não puderam confirmar a validade dos escores dessa subescala, chegando a propor sua eliminação, o que foi realmente adotado em seus dois estudos seguintes, que confirmaram a validade preditora do restante do questionário. Como possível alternativa, o constructo subjacente a essa medida nem caberia no continиит dos quatro estilos, mas constituiria um estilo específico - promotor de motivação por comparação social. Mesmo que esse estilo possa ser interpretado como uma forma de baixo controle, tanto os dados do presente estudo como as descobertas anteriores sugerem sua exclusão ou uma revisão radical de seus itens.

Já a subescala correspondente ao fator 3 poderia, com certeza, constituir-se na única forma intermediária entre o estilo altamente promotor de autonomia e o estilo altamente controlador. Seria convenientemente rotulada de estilo parcialmente promotor de autonomia, ou algo similar.

As dificuldades encontradas quanto à validade de constructo da presente escala não devem causar surpresa, pois fazem parte de todo processo de elaboração e construção de escalas. Problems in Schools é um instrumento relativamente novo, pouco trabalhado e que aparentemente nunca foi retomado pelos seus próprios autores. Segundo a orientação de Cronbach (1996), conhecido especialista em medidas psicológicas, existem casos em que é necessário rever o constructo, mesmo quando o teste for considerado válido. Segundo ele, nenhuma interpretação é a palavra final, estabelecida para sempre:

\begin{abstract}
A validação do constructo é um processo fluido, criativo. $O$ construtor do teste ou qualquer investigador subseqüente trabalha para desenvolver uma interpretação, persuadir os outros de sua adequação e revisá-la sempre que forem reconhecidos aspectos inadequados. A autocrítica e a crítica das pessoas que preferem outras interpretações desempenham um papel importante. A interpretação tem aspectos científicos, mas ela freqüentemente inclui políticas e sugere ações práticas. Essa complexidade significa que a validação não pode ser reduzida a regras. ( p. 166).
\end{abstract}

Pesquisas que tenham por objetivo identificar estratégias de ensino que promovam a autonomia de alunos poderiam utilizar o presente instrumento, valendo-se das sugestões acima expostas em relação à composição dos itens e à seleção e denominação das subescalas. Adicionalmente, novos procedimentos poderiam contribuir para o progresso na avaliação daqueles constructos.

Em primeiro lugar, os escores obtidos com a sua aplicação, feitas as reformulações aqui sugeridas, poderiam novamente ser submetidos a uma análise fatorial confirmatória. Adicionalmente, a validade de constructo deveria ser buscada, por exemplo, em estudos que correlacionassem os resultados com esse instrumento com os resultados obtidos com outras 
medidas já validadas. Outra forma de validação dos constructos seria conseguida com a observação e registro de comportamentos de professores em sala de aula, ou com dados obtidos de auto-relatos de seus respectivos alunos. Métodos qualitativos poderiam ocasionar maior refinamento na coleta de dados, como foi recentemente sugerido por Reeve e cols. (1999), bem como por Aldridge, Frasear e Huang (1999). Em seu estudo, estes últimos autores realizaram entrevistas e análises sobre narrativas de professores, objetivando uma interpretação mais aprimorada de suas percepções e sentimentos a respeito de situações de ensino que compunham o instrumento a ser validado naquela situação.

\section{Referências}

Aldridge, J M., Fraser, B, J., Huang, T. I. (1999). Investigating classroom environ-ments in Taiwan and Australia with multiple research methods. Journal of Educational Research, 93(1), 48-63.

Cronbach, L.J. (1996). Fundamentos da testagem psicológica. Porto Alegre: Artes Médicas.

Deci, E.L. \& Ryan, R.M. (1985). Intrinsic motivation and self-determination in human behavior. New York: Plenum.

Deci, E.L., Schwartz, A.J, Sheinman, L. \& Ryan, R.M. (1981). An instrument to assess adults' orientations toward control versus autonomy with children: reflections on intrinsic motivation and perceived competence. Journal of Educational Psychology, 73(5), 642-650.

Deci, E. L., Spiegel, N. H., Ryan, R. M., Koestner, R., Kauffman, M. (1982). Effects of performance standards on teaching styles: behavior of contolling teachers. Journal of Educational Psychology, 74(6), 852-859.

Flink, C., Boggiano, A.K. \& Barrett, M. (1990). Controlling teaching strategies: undermining children's self-determination and performance. Journal of Personality and Social Psychology, 59 (5), 916-924.
Guay, F.; Boggiano, A.K.; Vallerand, R. J. Autonomy support, intrinsic motivation, and perceived competence: conceptual and empirical linkages. Personality and Social Psychology Bulletin, v. 27, n. 6, p. 643-650, 2001.

Guimarães, S.E.R. (2000). Motivação intrínseca, extrínseca e o uso de recompensas em sala de aula. Em E. Boruchovitch \& J.A. Bzuneck (Orgs.) A motivação do aluno. Contribuições da psicologia contemporânea (pp.37-57). Petrópolis: Vozes.

Kline, P. (1994) An easy guide to factor analysis. New York: Routledge.

Lepper, M. R. \& Hodell, M. (1989). Intrinsic motivation in the classroom. Em C. Ames \& R. Ames (Orgs.) Research on Motivation in Education, Vol.03, Goals and Cognitions (pp.73-105).New York: Academic Press.

Pelletier, L. G.; Sèguin-Levesque, C.; Legault, L. Pressure from above and pressure from below as determinants of teachers' motivation and teaching behaviors. Journal of Educational Psychology, v.94, n.1, p. 186-196, 2002.

Reeve, J. (1998). Autonomy support as an interpersonal motivating style: is it teacheble? Contemporary Educational Psychology, 23, 312-330.

Reeve, J., Bolt, E. \& Cai, Y. (1999). Autonomy supportive teachers: how they teach and motivate students. Journal of Educational Psychology, 91, 537-548.

Ryan, R.M. \& Deci, E.L. (2000). Self-determination theory and the facilitation of intrinsic motivation, social development, and well-being. American Psychologist, 55 (1), 68-78.

Woolfolk, A. E. \& Hoy, W.K. (1990). Prospective teachers' sense of efficacy and beliefs about control. Journal of Educational Psychology, 82 (1), 81-91.

Yi Cai; Reeve, J.; Robinson, D. T. Home schooling and teaching style: comparing the motivating styles of home school and public school teachers. Journal of Educational Psychology, v. 94, n.2, p.372-380, 2002. 